\title{
PRELIMINARY RESULTS AND CONCLUSIONS FROM MATHEMATICAL MODELLING OF THERMAL REGIME OF RAILWAY TRACK STRUCTURE
}

\author{
S. HODAS, L. IŽVOLT \& P. DOBEŠ \\ University of Žilina, Faculty of Civil Engineering, Department of Railway Engineering and Track Management, \\ Žilina, Slovakia
}

\begin{abstract}
The paper characterizes the existing results and preliminary conclusions of mathematical modelling of the thermal regime of railway track structure carried out on the experimental stand and optimizes the structural thickness of the protective layer in the subgrade structure by the SVHEAT SoilVision software. SoilVision system is a modelling software based on the finite element method developed for geotechnical engineers. The first part describes the experimental stand design and methodology for monitoring the heat and humidity variations in the railway track structure [1]. This paper section characterizes the results of mathematical modelling of the thermal regime of the railway track model and subsequently carries out a comparison of results of experimental measurements and mathematical modelling by the SVHEAT [2]. The paper enables mathematical modelling of various combinations of material compositions of railway track structure after entering all the relevant input data of the winter periods. In this way, conditions for drawing up the relevant design nomograms for various types of subgrade structure or railway body types are created.

Keywords: mathematical modelling of thermal regime, railway subgrade, railway track, SVHEAT SoilVision.
\end{abstract}

\section{INTRODUCTION}

This research is carried out using experimental stands of railway track models and software support for mathematical modelling of the thermal regime and variations in humidity of railway track structure.

The second part of our research (Department of Railway Engineering and Track Management - DRETM) [3] characterizes the results of mathematical modelling of the thermal regime of the railway track model and subsequently carries out a comparison of results of experimental measurements [1] and mathematical modelling. It also introduces the preliminary design nomogram for determining the structural thickness of the protective layer of subgrade surface.

As at the time of construction of the experimental stand DRETM II, the software for mathematical modelling of the subgrade thermal regime was available, besides higher number of thermal sensors, humidity sensors were also embedded to acquire one of the input parameters for mathematical modelling of the thermal regime using SoilVision software. This parameter, that substantially influences the thermal regime of the rail track structure and also the depth of subgrade freezing, is necessary for mathematical modelling of the subgrade thermal regime using the SoilVision software. 


\section{MATHEMATICAL MODELLING OF THERMAL REGIME OF THE EXPERIMENTAL STAND DRETM II USING THE SOILVISION SOFTWARE}

The determination of thermo-technical characteristics of construction materials is one of the inevitable prerequisites for objective mathematical modelling of the thermal regime of a railway track. On the basis of verification of thermal conductivity coefficients $\lambda$ and the so far carried out measurements of variations in humidity of materials built in the experimental stand DRETM II, we suggest considering the following values of thermal conductivity coefficients $\lambda$ (Table 1) and design values of material humidity (Table 2) of structural layers of the experimental stand DRETM II.

SoilVision is modelling software based on the finite element method developed for geotechnical engineers. This software consists of six program products: SVFLUX, SVSLOPE, CHEMFLUX, SVSOLID, SVAIRFLOW and SVHEAT [2]. The most suitable software product for experimental modelling of the thermal regime of railway track structure is SVHEAT. It serves for modelling the convection or conduction of heat in saturated or unsaturated soils and enables complete settings of model specifications, including the climatology of winter conditions.

\section{CHARACTERISTICS OF PRINCIPLES AND INPUTS OF MATHEMATICAL MODELLING}

To mathematically model the thermal regime of railway track (subgrade) and the verification of effects of individual factors in its course, in the case of the experimental stand DRETM II two railway track models were created (Figs 1 and 2). Figure 1 demonstrates the mathematical model of the one measuring profile of the respective experimental stand (including the protective layer in the railway track model structure). Figure 2 shows the second measuring profile (without the protective layer) of the experimental stand.

After creating the so-called basic structural model of railway track in SVHEAT program, it is possible to specify further input and boundary conditions, including:

Table 1: Design values of thermal conductivity coefficients $\lambda$.

\begin{tabular}{lc}
\hline Material & $\begin{array}{c}\text { Thermal conductivity coefficient } \lambda_{\text {design }} \\
\left(\mathrm{W} \cdot \mathrm{m}^{-1} \cdot \mathrm{K}^{-1}\right)\end{array}$ \\
\hline Rail gravel & 1.20 \\
Gravel sand & 2.30 \\
Crushed aggregate fr. $0 / 31.5 \mathrm{~mm}$ & 2.00 \\
Crushed aggregate fr. $0 / 63 \mathrm{~mm}$ & 1.70 \\
Clay with addition of river gravel & 1.00 \\
\hline
\end{tabular}

Table 2: Design values of material humidity of structural layers in the experimental stand DRETM II.

\begin{tabular}{lc}
\hline Material & Humidity $w_{m}(\%)$ \\
\hline Rail bed & 1.3 \\
Crushed aggregate fr. $0 / 31.5 \mathrm{~mm}$ & 5.0 \\
Crushed aggregate fr. $0 / 63 \mathrm{~mm}$ & 5.0 \\
Clay with the addition of river gravel & 16.0 \\
\hline
\end{tabular}




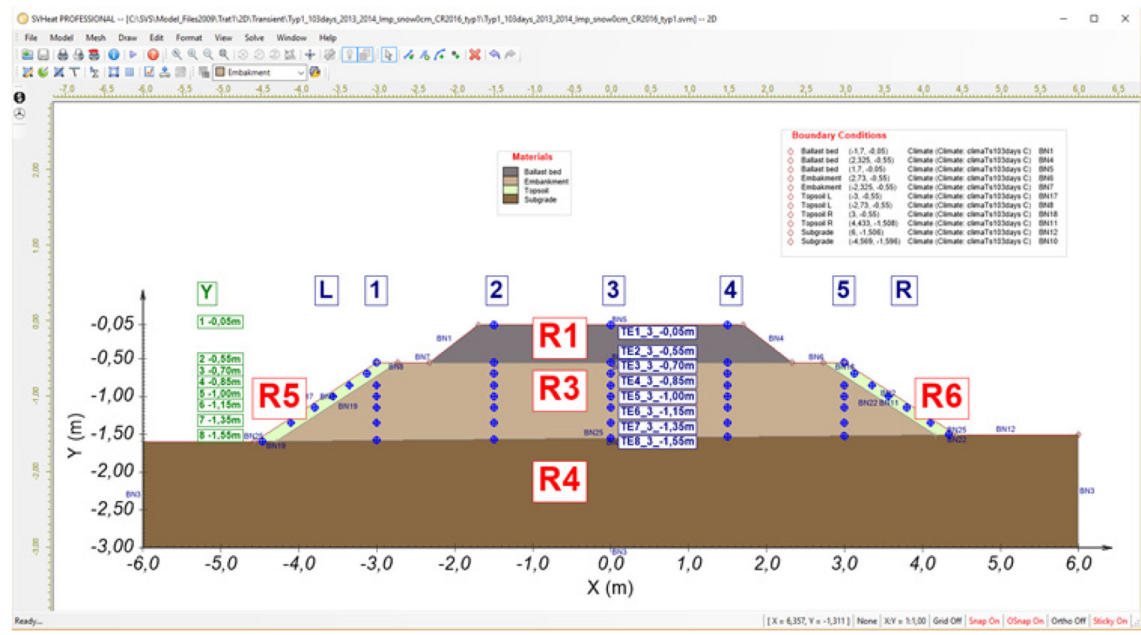

Figure 1: Model of the experimental stand DRETM II - 1st measuring profile.

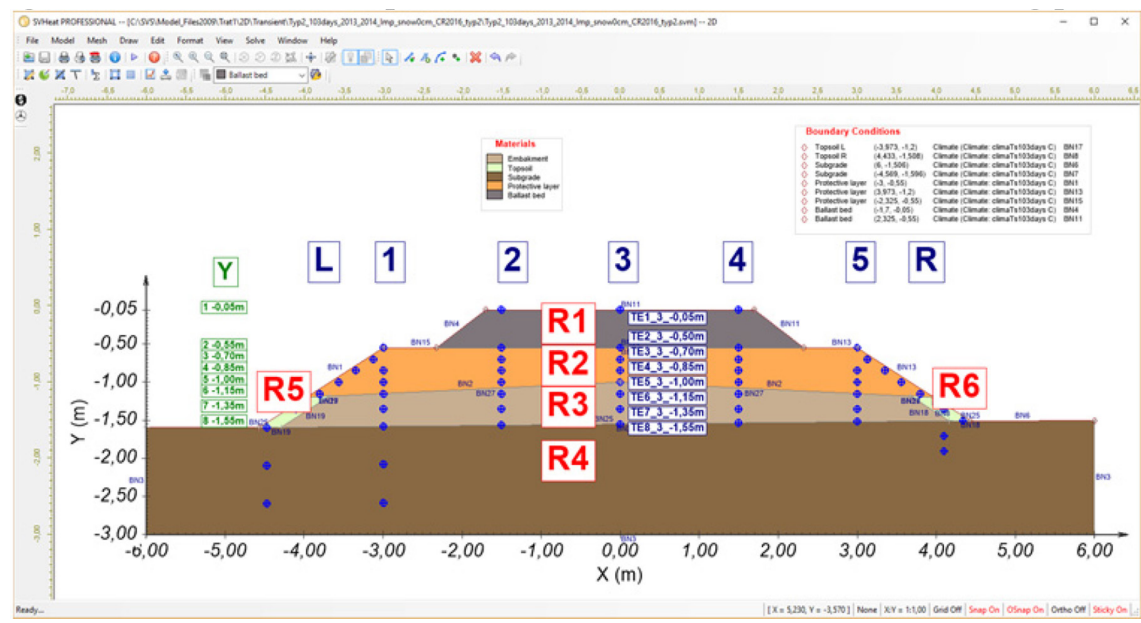

Figure 2: Model of the experimental stand DRETM II - 2nd measuring profile.

- initialization of thermal conditions of the model,

- climatic conditions affecting the model,

- boundary conditions acting on the edges of the model,

- specification of the material used in the structural layers of the model.

The initial setting of the thermal conditions can be done either by direct setting of the measured temperatures for a monitored period and for individual regions in the model (as in our case), or it is possible to set them with the help of an equation, constant value, network of points or the list of tables of measured data.

Another very important step in the mathematical modelling of the thermal regime of the railway track is setting the climatic conditions. With regard to the fact that the goal is to localize the position of the zero isotherm, only the winter period values are selected, includ- 
ing the presence of snow cover on the railway track model surface. The outer temperatures are measured $2.00 \mathrm{~m}$ above the terrain surface and on the surface of the railway track model (there is a possibility of conversion between the given parameters using the constant value or $\mathrm{n}$-factor). For mathematical modelling, we use the values of daily mean temperature determined using the eqn (1) [3].

The mean daily temperature $\theta_{s} i$ calculated from the air temperatures, measured at 7 a.m., 2 p.m. and 9 p.m. from the eqn (1):

$$
\theta_{s}=\frac{\theta_{7}+\theta_{14}+2 \theta_{21}}{4}
$$

In case we substitute the value of air temperature on the terrain (rail bed) surface for the mean daily air temperature $\theta_{s}$ into the eqn (1), we gain the frost index on the surface $I_{F S}$. The basic characteristics of the winter period is the total value of the frost index, that we get by addition of mean daily air temperatures in the winter period (totalizing curve in ${ }^{\circ} \mathrm{C}$ is acquired) using the eqn (2):

$$
I_{F}=\sum_{t_{b}}^{t_{f}} \theta_{s}
$$

The thickness of the snow cover in the model can be set as a constant value for all the winter period, can be specified for individual days, or it can be set using the n-factor. In our case the height of the snow cover was set in the thickness of $120 \mathrm{~mm}$ or lower, when under the influence of thaw its thickness as well as its thermal insulation effects on lower-laying structural layers of railway track are naturally decreasing. Besides the mentioned possibility of setting the values of snow cover, it is possible to set the snowfall, snow melting, etc.

For all the edges of regions $B N_{i}$, defined by colour differentiation of individual regions (Figs 1 and 2), the boundary conditions are set. For the transition of temperatures they can be set as:

- flux at the edges,

- data table of flux,

- constant transition,

- climatic conditions,

- inner or outer insulation, etc.

Among the most important edges we rank the top edges of regions (for example $B N_{12}{ }^{-}$ $B N_{15}, B N_{18}$ ), directly influenced by climatic conditions. In the case of application at the experimental stand DRETM II, the boundary conditions were set using the table values for temperatures during the particular winter period, including the existence of snow cover layer.

Concerning setting the model inputs, the last step is setting the materials applied on individual structural layers of the model. To mathematically model the thermal regime of the model at the experimental stand DRETM II, the real measured values were used. In the model, they were set in the form of a table.

The basic parameters set in the model are:

- conductivity coefficient $\lambda$,

- volumetric heat capacity $c$, 
- soil freezing characteristic curve (SFCC),

- volumetric water content $w_{m}$.

After specifying the input values, the program SVHEAT enables mathematical modelling of the thermal regime of the rail track structure.

\section{COMPARISON OF THE RESULTS OF THE THERMAL REGIME OF THE EXPERIMENTAL STAND DRETM II}

The comparison of the acquired results of the course of the thermal regime of the structure applied in the experimental stand DRETM II to the results of the mathematical modelling of the thermal regime of an identical structure was carried out for the winter period 2014/2015. This winter period was analysed because if reached so far the highest air frost index $I_{F}=$ $-77^{\circ} \mathrm{C}$.day $\left(D_{F}=0,41 \mathrm{~m}\right)$ in the monitored period (the measured data were only for two winter periods with mild course). For specific mathematical modelling of the thermal regime, the main climatic condition was the mean daily temperature on the rail bed surface (that was set as a table for individual days). The thickness of the snow cover was not considered as the snow was removed during both winter periods to enable the maximum effects of frost on the monitored structure. The input parameters for the mathematical modelling of the thermal regime of the experimental stand DRETM II are clearly stated in Table 3.

The output of the mathematical modelling of the thermal regime for the values stated in Table 3 is the identification of the penetration (position) of the zero isotherm (light blue and pink boundary) into the railway track model structure. Its continuous penetration is obvious from Figs 3-5. Day 97 (TIME = 97) matches the date 19.02.2015, when the maximum frost depth $D_{F}$ of the monitored structure was reached.

Figure 5 clearly shows that the depth of freezing on the railway track model correlates with the depth of freezing reached in the experimental stand structure $D_{F}=0.41 \mathrm{~m}$ (see [1]) and the position of the zero isotherm can be located in the ballast bed area.

From the point of view of subgrade protection from the adverse effects of frost, the most critical and also the most monitored place is the subgrade surface. The comparison of temperatures reached by experimental measurements at the experimental stand $\left(\theta_{183}\right)$ to the temperatures acquired by mathematical modelling of the thermal regime of the identical

Table 3: Input parameters of materials of the structural layers of the experimental stand.

\begin{tabular}{|c|c|c|c|c|c|}
\hline Structural part/ characteristics & $\begin{array}{l}\text { Ballast } \\
\text { bed }\end{array}$ & $\begin{array}{l}\text { Protective } \\
\text { layer }\end{array}$ & Embankment & Subgrade & Topsoil \\
\hline Marking in the model & R1 & R2 & R3 & R4 & $\mathrm{R} 5,6$ \\
\hline Temperature $\theta\left({ }^{\circ} \mathrm{C}\right)$ & 8 & 11 & 12 & 13 & 8 \\
\hline Humidity $w_{m}(\%)$ & 1.3 & 6 & 6 & 16 & 20 \\
\hline $\begin{array}{l}\text { Specific heat capacity } c_{0} \\
\left(\mathrm{~J} \cdot \mathrm{kg}^{-1} \cdot \mathrm{K}^{-1}\right)\end{array}$ & 980 & 1,088 & 1,053 & 1,495 & $\begin{array}{l}1,639 \\
\left(1,305^{*}\right)\end{array}$ \\
\hline $\begin{array}{l}\text { Volumetric capacity } \rho_{0} \\
\left(\mathrm{~kg} \cdot \mathrm{m}^{-3}\right)\end{array}$ & 1,908 & 1,928 & 2,091 & 1,646 & 1,320 \\
\hline $\begin{array}{l}\text { Thermal conductivity } \\
\text { coefficient } \lambda\left(\mathrm{W} \cdot \mathrm{m}^{-1} \cdot \mathrm{K}^{-1}\right)\end{array}$ & 1.2 & 1.93 & 1.69 & 0.81 & $\begin{array}{l}1.13 \\
\left(1.35^{*}\right)\end{array}$ \\
\hline
\end{tabular}

* values for frozen material. 


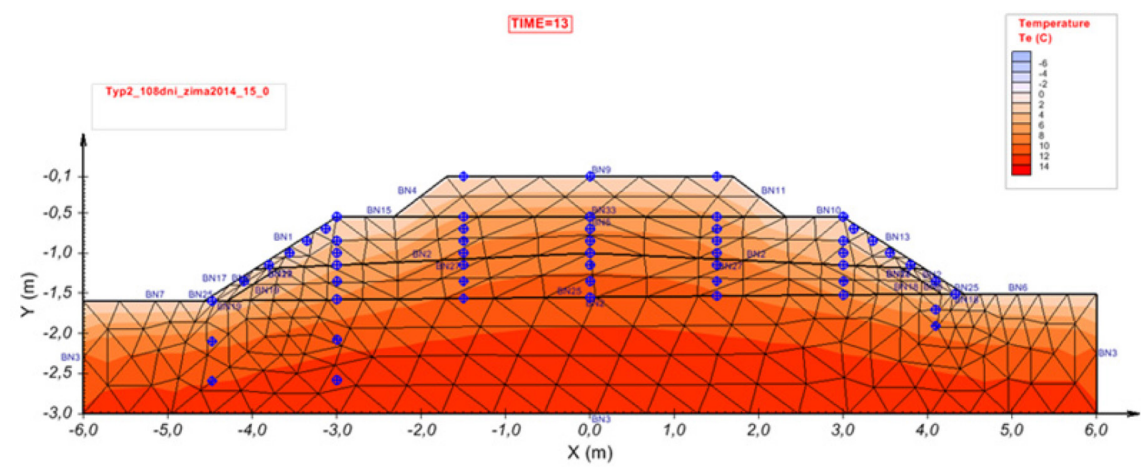

Figure 3: Graphic output of modelling the freezing of the model structure of the experimental stand - winter 2014/2015 (influence of the first negative mean temperature).

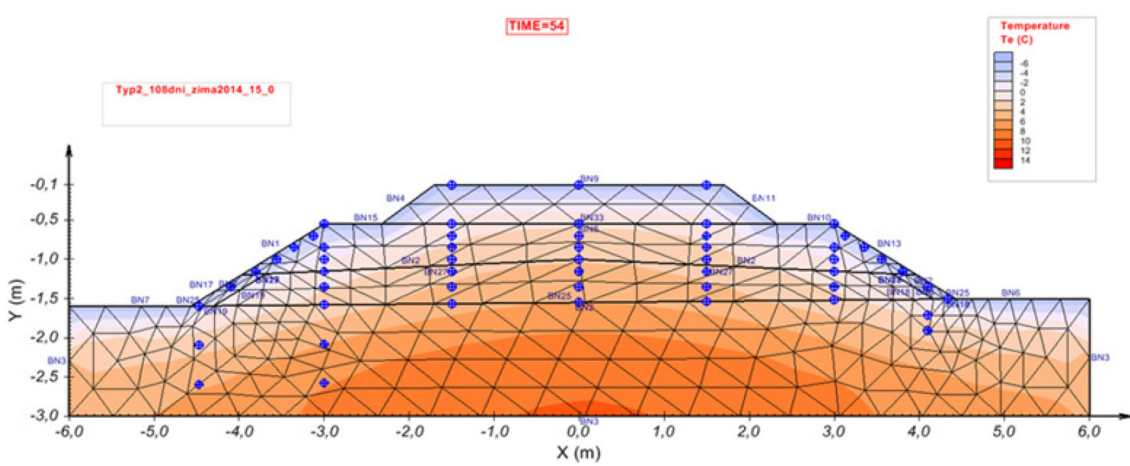

Figure 4: Graphic output of modelling the freezing of the model structure of the experimental stand - winter 2014/2015 (influence of the maximum negative mean daily temperature).

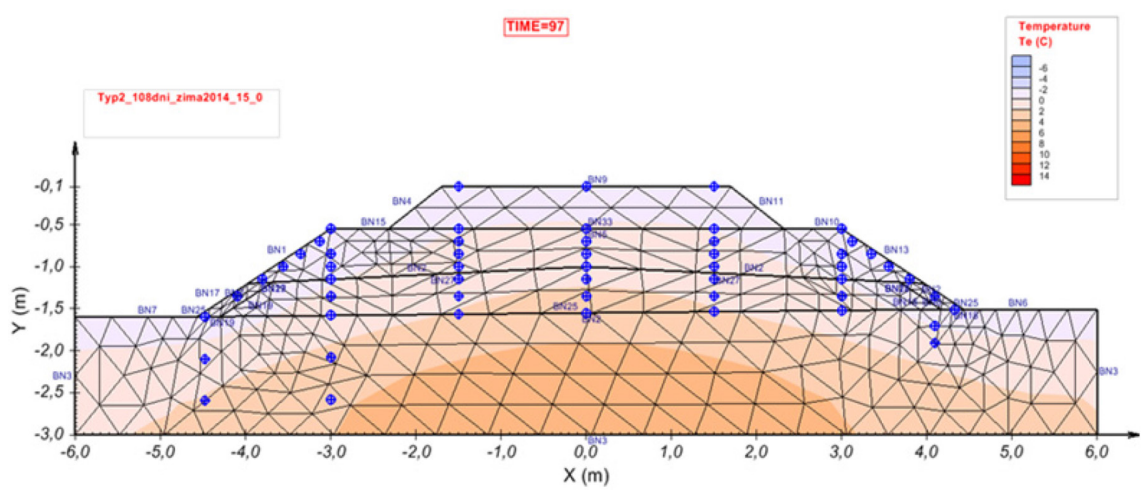

Figure 5: The graphic output of modelling the freezing of the experimental stand structure winter 2014/2015 (reaching the maximum freezing depth). 


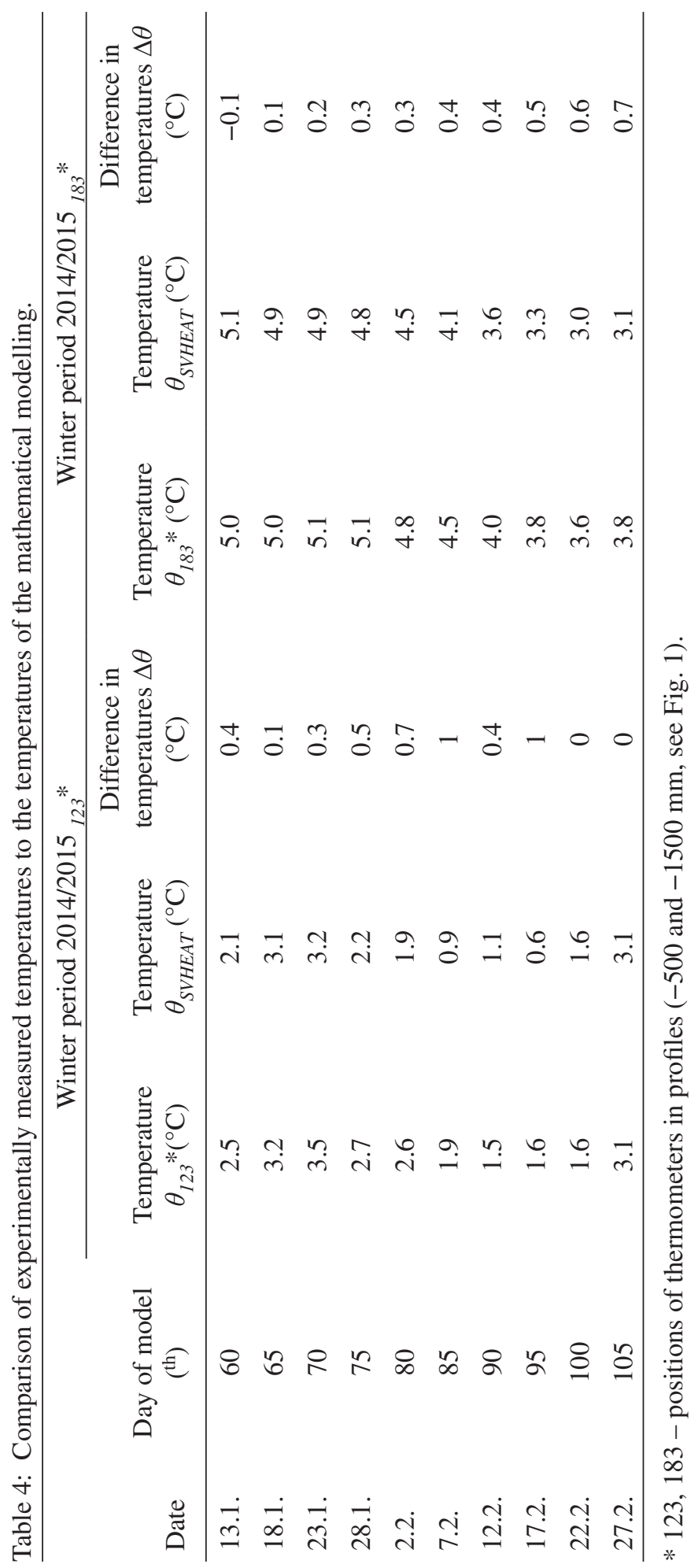


structure of the experimental stand $\left(\theta_{\text {SVHEAT }}\right)$ was carried out each 5 days, from the 60th to the 105th days of the winter period (see Table 4). As the zero isotherm did not penetrate below the ballast bed level, (to the substructure level), besides this comparison, the comparison of the temperatures at the railway substructure level was also carried out. The temperature differences $(\Delta \theta)$ between the experimentally measured temperature values $\left(\theta_{i}\right)$ and the temperatures acquired by mathematical modelling of the thermal regime $\left(\theta_{\text {SVHEAT }}\right)$ of thermometers positions were found in the same interval as for the compared thermometers.

Table 4 shows that the experimentally measured temperatures and the temperatures of mathematical modelling of the thermal regime of the experimental stand for both winter periods differed in the range up to $\pm 1.0^{\circ} \mathrm{C}$, on both monitored levels (the level of the railway substructure as well as the subgrade surface level).

\section{MATHEMATICAL MODELLING OF INFLUENCE OF NON-TRAFFIC LOAD ON THE THERMAL REGIME OF THE EXPERIMENTAL STAND DRETM II}

The area of the Slovak Republic from the point of view of climatology is a diverse one, as there are lowland areas (higher temperatures during the year), but also high mountain areas (lower temperatures during the year), where the attained frost index values during the winter period in our territory vary in the range from $-300^{\circ} \mathrm{C}$.day to $-800^{\circ} \mathrm{C}$.day. The average annual temperatures in Slovakia are in the range of from $0^{\circ} \mathrm{C}$ to $10^{\circ} \mathrm{C}$, while for the areas of operated

Table 5: Input parameters of mathematical modelling of the thermal regime of the experimental stand.

Material characteristics

\begin{tabular}{|c|c|c|c|c|c|c|}
\hline $\begin{array}{l}\text { Structural part charac- } \\
\text { teristics }\end{array}$ & $\begin{array}{l}\text { Ballast } \\
\text { bed }\end{array}$ & \multicolumn{2}{|c|}{ Protective layer } & Embankment & Subgrade & Topsoil \\
\hline Marking in the model & $\mathrm{R} 1$ & \multicolumn{2}{|l|}{$\mathrm{R} 2$} & $\mathrm{R} 3$ & $\mathrm{R} 4$ & $\mathrm{R} 5,6$ \\
\hline Temperature $\left({ }^{\circ} \mathrm{C}\right)$ & 2 & \multicolumn{2}{|l|}{5} & 6 & 7 & 1 \\
\hline Humidity $w_{m}(\%)$ & 1.3 & \multicolumn{2}{|l|}{5} & 5 & 16 & 20 \\
\hline 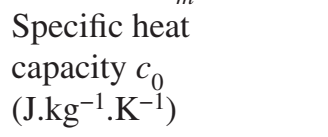 & 980 & \multicolumn{2}{|c|}{1,088} & 1,053 & 1,495 & $\begin{array}{l}1,639 \\
\left(1,305^{*}\right)\end{array}$ \\
\hline $\begin{array}{l}\text { Volumetric capacity } \\
\rho_{0}\left(\mathrm{~kg} \cdot \mathrm{m}^{-3}\right)\end{array}$ & 1,908 & \multicolumn{2}{|c|}{1,928} & 2,091 & 1,646 & 1,320 \\
\hline $\begin{array}{l}\text { Thermal conductivity } \\
\text { coefficient } \lambda \\
\left(\mathrm{W} \cdot \mathrm{m}^{-1} \cdot \mathrm{K}^{-1}\right)\end{array}$ & 1.2 & \multicolumn{2}{|l|}{1.55} & 1.42 & 0.81 & $\begin{array}{l}1.13 \\
\left(1.35^{*}\right)\end{array}$ \\
\hline \multicolumn{7}{|l|}{ Climatic characteristics } \\
\hline $\begin{array}{l}\text { Average annual } \\
\text { temperature } T_{m}\left({ }^{\circ} \mathrm{C}\right)\end{array}$ & 5 & 6 & 7 & 8 & 9 & 10 \\
\hline $\begin{array}{l}\text { Air frost index } I_{F} \\
\left({ }^{\circ} \text { C.day }\right)\end{array}$ & -800 & -700 & -600 & -500 & -400 & -300 \\
\hline
\end{tabular}

* values for frozen material. 
railway tracks the attained average annual temperatures are in the range of from $5^{\circ} \mathrm{C}$ to $10^{\circ} \mathrm{C}$ (lower average annual temperatures are only in the high mountain areas).

The air frost indices $I_{F}$ are acquired by evaluating the data from experimental measurements at the experimental stand DRETM II. Unfortunately, they do not cover all the above-stated range of frost indices (max. value $I_{F}=-77^{\circ} \mathrm{C}$.day). To mathematically model the thermal regime, the data of mean daily temperatures was requested from SHMÚ (Slovak Hydrometeorological Institute), for the winter period 1995/1996 measured in Poprad $\left(I_{F}=\right.$ $-713^{\circ} \mathrm{C}$.day and $T_{m}=5^{\circ} \mathrm{C}$ ). In Poprad there is one of the highest situated railway stations, where the climatic characteristics are also monitored. By adjusting of mean daily air temperatures $\theta_{s}$ in the respective winter period, a set of climatic characteristics used for mathematical modelling of the thermal regime of the experimental stand was created. The input parameters for mathematical modelling of the thermal regime are stated in Table 5.

The thickness of the protective layer in the experimental stand DRETM II structure was dimensioned for the design frost index $-550^{\circ} \mathrm{C}$.day. As for the mathematical modelling of the thermal regime also the higher frost index $I_{F}$ values were used, it was necessary to adjust the thickness of the protective layer. The thickness of the protective layer was stated on the basis of the currently valid nomogram stated in [1], in the value of $0.60 \mathrm{~m}$. The adjusted model of the experimental stand DRETM II is shown in Fig. 1.

Also in this case of mathematical modelling, the influence of change of one of the input parameters on the thermal regime of the railway track model (air frost index $I_{F}$ or the average annual temperature $\theta_{m}$ ) was always individually monitored. It is necessary to point out that the time units in the model are set in the way that the marking TIME $=1$ always matches January, 1, TIME $=365$ matches December, 31 (to consider the influence of the average annual temperature $\theta_{m}$ ). The marking TIME $=328-478$ (for 150-day frost period) matches the frost period length in the respective winter period (to consider the influence of the air frost index $I_{F}$ ). The output of modelling the thermal regime for values stated in Table 5 is the identification of the penetration (position) of the zero isotherm to the model structure of railway track, that is obvious from Fig. 6 and which represents the case of influence of the worst climatic conditions $\left(I_{F}=-800^{\circ} \mathrm{C}\right.$. day and $\left.\theta_{m}=5^{\circ} \mathrm{C}\right)$.

On the basis of mathematical modelling of freezing, the railway track model and identification of the zero isotherm position (light pink and blue boundary), subsequently there could

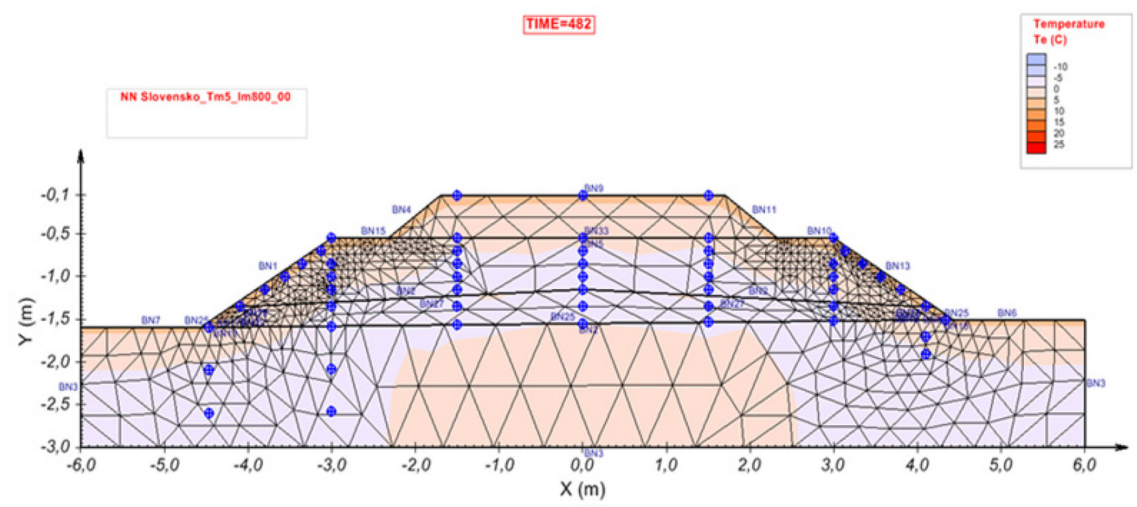

Figure 6: Graphic output of modelling the freezing of the model structure of the experimental stand for $\theta_{m}=5^{\circ} \mathrm{C}$ and $I_{F}=-800^{\circ} \mathrm{C}$.day. 
Table 6: The necessary thicknesses of the protective layer of subgrade surface.

\begin{tabular}{lllllllll}
\hline & \multicolumn{7}{c}{ Air frost index $I_{F}\left({ }^{\circ} \mathrm{C}\right.$. day $)$} \\
\cline { 3 - 8 } & & -300 & -400 & -500 & -600 & -700 & -800 \\
\hline $\begin{array}{l}\text { Average annual temperature } \\
\theta_{m}\left({ }^{\circ} \mathrm{C}\right)\end{array}$ & 5 & & & & & 0.810 & 0.990 \\
& 6 & & & & 0.495 & 0.700 & 0.815 \\
& 7 & & & 0.340 & 0.450 & 0.555 & \\
& 8 & & 0.210 & 0.295 & 0.390 & & \\
& 9 & 0.080 & 0.180 & 0.240 & & & \\
& 10 & 0.065 & 0.155 & & & & \\
\hline
\end{tabular}

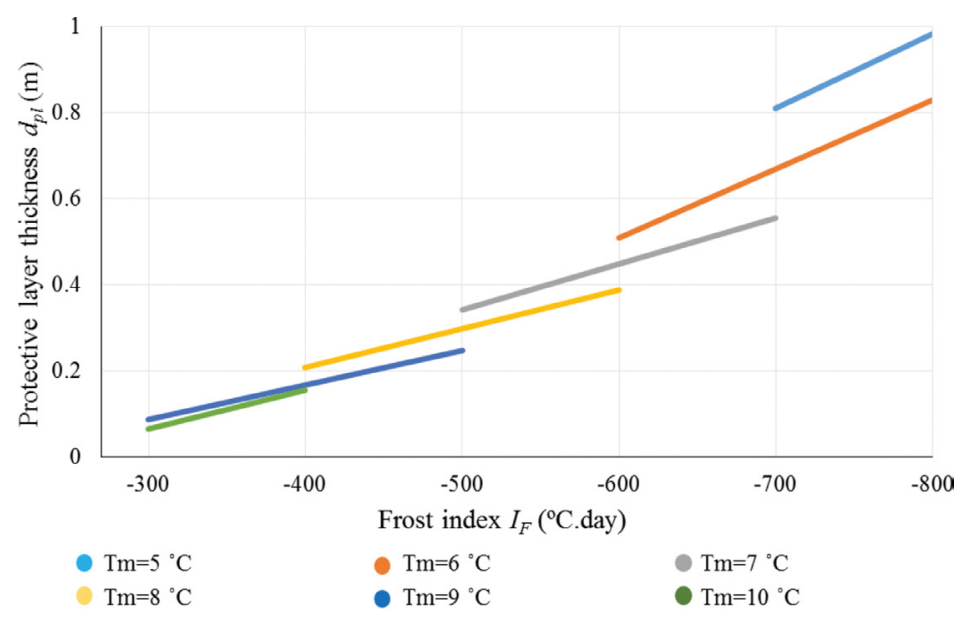

Figure 7: Determination of dependence of protective layer thickness on the average annual temperature $\theta_{m}$ and the frost index $I_{F}$ (preliminary design nomogram).

be deduced the necessary thicknesses of the protective layer of subgrade surface depending on the change of the air frost index $I_{F}$ and the average annual temperature $\theta_{m}$ - Table 6 .

On the basis of values stated in Table 6 and [1] the dependence of the depth of the protective layer of subgrade surface on the non-traffic load for the Slovak territory (preliminary design nomogram), stated in Fig. 7 was created.

\section{CONCLUSION}

The SoilVision software enables mathematical modelling of various combinations of material compositions of railway track structure after entering all the relevant input data. In this way, conditions for drawing up the relevant design nomograms for various types of subgrade structure or railway body types $[1,4-6]$ are created. 
In the near future, the project attention [7] will be focused on modelling and measuring the models of the railway track in embankment. A real disadvantage of this model is that it cannot be modified during the long period measurements. Conversely, the advantage of the model analysis in SVHEAT [2] is a simple modification of layers composed of different variant materials, e.g. concrete slab tracks, using various geosynthetics and concrete substrates [6], and the like.

\section{ACKNOWLEDGEMENT}

The presented results and conclusions are the results of solving the VEGA grant project VEGA 1/0275/16 Design optimization of sleeper subgrade due to non-traffic load aspect [7].

\section{REFERENCES}

[1] Ižvol, L., Dobeš, P. \& Pitoňák, M., Preliminary results and conclusions from the experimental monitoring of thermal regime of railway track structure. Proceedings of the COMPRAIL 2016 - 15th International Conference on Railway Engineering Design \& Operation, WESSEX Institute of Technology: Madrid, Spain, http://www.wessex. ac.uk, WitPress, http://www.witpress.com, Southampton, United Kingdom, 2016.

[2] SVHEAT 2D/3D Geothermal Modelling, SVOFFICE 2009 - Geotechnical Modelling Suite, SoilVision systems Ltd., http://www.soilvision.com, Saskatoon, Saskatchenwan, Canada, 2016.

[3] VEGA 1/0756/12 Experimental monitoring and mathematical modelling of thermal regime of railway subgrade structure. Scientific Research of Dept. of Railway Engineering, Fac. of Civil Engineering, University of Žilina, Žilina, http://svf.uniza.sk/kzsth. VEGA - Ministry of Education, Science \& Research of the Slovak Republic, http:// www.minedu.sk, Bratislava, SK, 2012-2015.

[4] Ižvolt, L., Dobeš, P. \& Pitoňák, M., Some experience and preliminary conclusions from the experimental monitoring of the temperature regime of subgrade structure. Proc. of the COMPRAIL XIV Computer in Railways - Railway Engineering Design and Optimization, WITpress, http://www.witpress.com, WIT transactions on the built environment, 135, pp. 267-278, 2014. http://dx.doi.org/10.2495/CR140211

[5] Hodas, S. \& Ižvolt, L., Modelling of temperature regime of railway track structure and its comparison with the results of experimental measurements. Proc. of the COMPRAIL XIV Computer in Railways - Railway Engineering Design and Optimization, Rome, Italy, WESSEX Institute of Technology, http://www.wessex.ac.uk WitPress, 135, http:// www.witpress.com Southampton, United Kingdom, pp. 253-265, 2014. http://dx.doi.org/10.2495/CR1402014

[6] Hodas, S., Design of railway track for speed and high-speed railways. Proc. of the XXIII Russian - Slovak - Polish Seminar, Theoretical Foundation of Civil Engineering, Procedia Engineering, 91, online http://www.sciencedirect.com/ science/article/pii/ S1877705814030744\#, pp. 256-261, 2014. http://dx.doi.org/10.1016/j.proeng.2014.12.056.

[7] VEGA 1/0275/16 Design optimization of sleeper subgrade due to non-traffic load aspect. Scientific Research of Dept. of Railway Engineering, Fac. of Civil Engineering, University of Žilina, Žilina, http://svf.uniza.sk/kzsth VEGA - Ministry of Education, Science \& Research of the Slovak Republic, http://www.minedu.sk Bratislava, SK, 2016-2019. 